\title{
13.3;06.5
}

\section{Исследование приповерхностного слоя германия, имплантированного ионами кобальта}

\author{
(c) В.В. Базаров ${ }^{1}$, В.А. Шустов ${ }^{1}$, Н.М. Лядов ${ }^{1}$, И.А. Файзрахманов ${ }^{1}$, И.В. Янилкин ${ }^{1,2}$, С.М. Хантимеров ${ }^{1}$, \\ P.P. Гарипов ${ }^{1}$, Р.P. Фатыхов ${ }^{1}$, Н.М. Сулейманов ${ }^{1,3}$, В.Ф. Валеев ${ }^{1}$ \\ ${ }^{1}$ Казанский физико-технический институт им. Е.К. Завойского ФИЦ „Казанский научный центр РАН“, Казань, Россия \\ ${ }^{2}$ Казанский (Приволжский) федеральный университет, Казань, Россия \\ ${ }^{3}$ Казанский государственный энергетический университет, Казань, Россия \\ E-mail: vbazarov1@gmail.com
}

Поступило в Редакцию 26 июня 2019г.

В окончательной редакции 26 июня 2019 г.

Принято к публикации 3 июля 2019 г.

\begin{abstract}
Представлены результаты исследования наноструктурированной ионной имплантацией поверхности германия. В эксперименте монокристаллические пластины германия $(c-\mathrm{Ge})$ облучались ионами $\mathrm{Co}^{+} \mathrm{c}$ энергией $40 \mathrm{keV}$ в интервале доз $(2-8) \cdot 10^{16} \mathrm{ion} / \mathrm{cm}^{2}$. Методом сканирующей электронной микроскопии исследована эволюция морфологии поверхности германия с увеличением дозы имплантации. Установлено, что с ростом дозы имплантации на поверхности имплантированного германия постепенно формируется слой сферических образований диаметром $\sim 150 \mathrm{~nm}$. Анализ спектров рентгеновской дифракции показал появление в имплантированном слое наноразмерных частиц германида кобальта (CoGe).
\end{abstract}

Ключевые слова: наноструктурированный германий, ионная имплантация, литий-ионные аккумуляторы.

DOI: 10.21883/PJTF.2019.20.48392.17949

На данный момент германий остается важным материалом для ряда приложений в микроэлектронных устройствах благодаря более высокой подвижности носителей и меньшей ширине запрещенной зоны, чем у кремния. При высокодозном ионно-имплантационном легировании $\mathrm{Ge}$ на его поверхности образуется пористый слой, толщина которого в несколько раз превышает средний пробег ионов $[1,2]$. Возможность создания на поверхности Ge нанопористой структуры привела к тому, что в последние годы наметилась тенденция применения Ge в новых областях техники: в литий-ионных батареях в качестве материала анода [3], в качестве новых материалов для газовых сенсоров [4] и оптоэлектронных приборов [5]. Пористый слой появляется при имплантации широкого спектра тяжелых ионов с энергиями в интервале от единиц до сотен $\mathrm{keV}$ при пороговой дозе имплантации около $10^{16} \mathrm{ion} / \mathrm{cm}^{2}$ [2]. В настоящей работе проведены исследования зависимости кристаллической структуры и фазового состава приповерхностного слоя монокристаллических пластин $\mathrm{Ge}$, подвергнутых ионному облучению ионами $\mathrm{Co}^{+}$с энергией $40 \mathrm{keV}$.

Объектами экспериментов служили монокристаллические $(c-\mathrm{Ge})$ германиевые подложки ГДГ-45 с ориентацией (111), имплантированные ионами $\mathrm{Co}^{+}$в интервале доз $D=(2-8) \cdot 10^{16} \mathrm{ion} / \mathrm{cm}^{2}$ с энергией $E=40 \mathrm{keV}$ и плотностью тока в ионном пучке $1-2 \mu \mathrm{A} / \mathrm{cm}^{2}$. Имплантация проводилась на ускорителе ионов ИЛУ-3 при остаточном вакууме $10^{-5}$ Torr.

Для наблюдения изменения морфологии поверхности германия с увеличением дозы имплантации была использована сканирующая электронная микроскопия (СЭМ). Исследование выполнялось с помощью сканирующего электронного микроскопа Carl Zeiss EVO50 XVP, съемка проводилась под углом $70^{\circ}$.

Микрофотографии поверхности пластины $\mathrm{Ge}$, имплантированной ионами $\mathrm{Co}^{+}$с дозами $(2.4,4.8,7.2) \cdot 10^{16} \mathrm{ion} / \mathrm{cm}^{2}$, представлены на рис. $1, a-c$. Можно заключить, что с увеличением дозы имплантации на поверхности имплантированного германия постепенно формируется слой сферических образований диаметром около $150 \mathrm{~nm}$. Начало формирования соответствует интервалу доз $(2.4-4.8) \cdot 10^{16} \mathrm{ion} / \mathrm{cm}^{2}$. Сформировавшиеся частицы обусловливают почернение поверхности имплантированного германия в видимом диапазоне длин волн, как это было отмечено в [2].

Для оценки толщины имплантированного слоя были проведены расчеты в программе компьютерного моделирования торможения ионов в веществе SRIM-2011 [6,7]. Моделирование дало следующие результаты: ионы $\mathrm{Co}^{+}$проникают в глубь поверхности Ge c максимумом статистического распределения Гаусса на глубине $R_{p} \sim 24 \mathrm{~nm}$, при этом распределение имеет среднеквадратичное отклонение $\Delta R_{p} \sim 14 \mathrm{~nm}$. Таким образом, размеры сферических образований, наблюдаемых в эксперименте, более чем в 5 раз превышают пробег ионов $\mathrm{Co}^{+}$в $\mathrm{Ge}$. Объяснение данного явления, по-видимому, состоит в том, что рост полученных сферических образований происходит в приповерхностном пористом слое германия аналогично росту углеродных нанотрубок или росту наноигл как результат распыления атомов с поверхности пор и последующего их осаждения $[1,8]$.

Для качественного определения фаз, входящих в состав полученных слоев, был использован метод рентгенофазового анализа. Исследования проводились на 

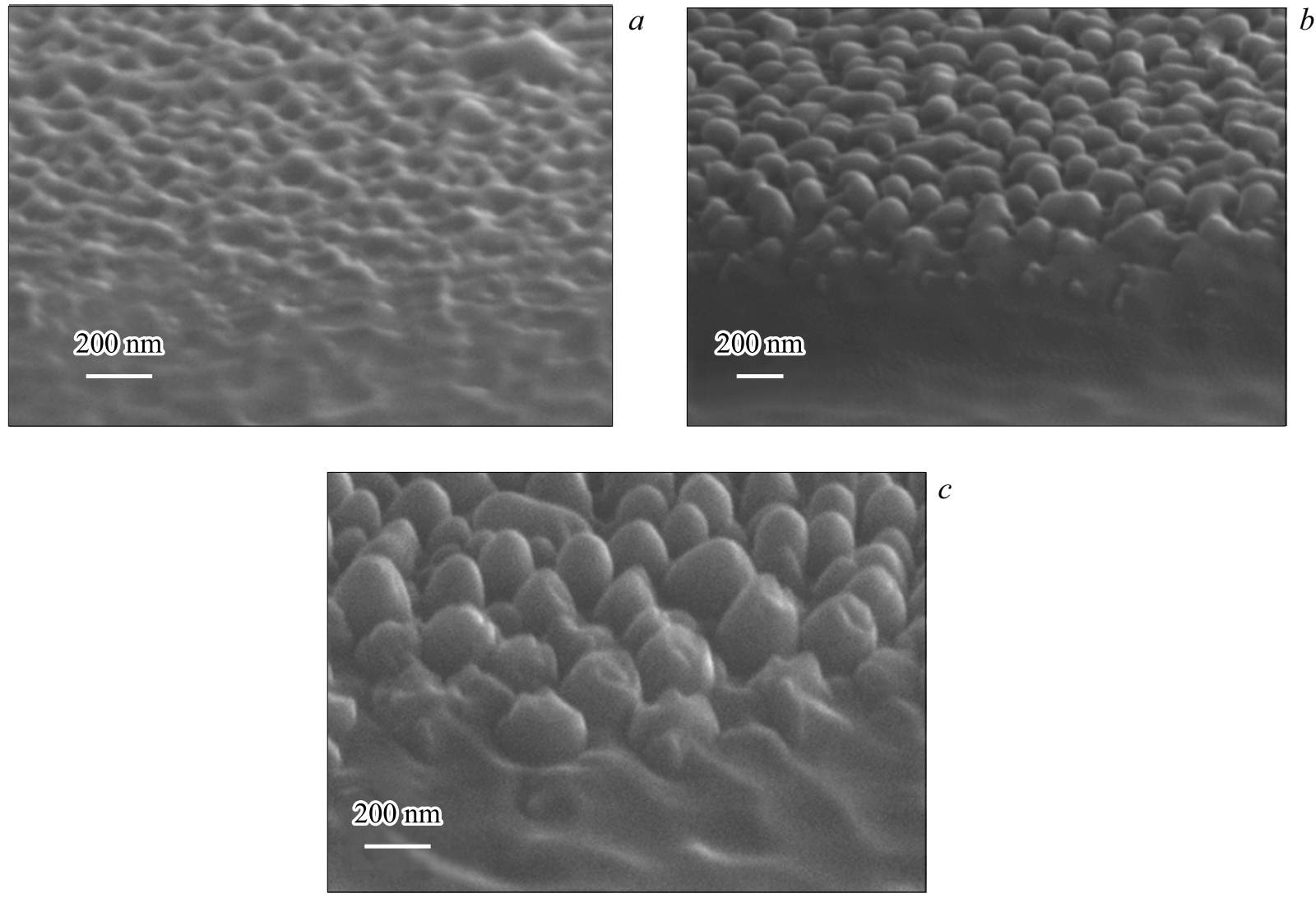

Рис. 1. СЭМ-изображения поверхности пластины $\mathrm{Ge}$, имплантированной ионами кобальта. Доза ионов $\mathrm{Co}^{+}, 10^{16}$ ion $/ \mathrm{cm}^{2}: a-2.4$, $b-4.8, c-7.2$. Изображения получены под углом $70^{\circ}$.

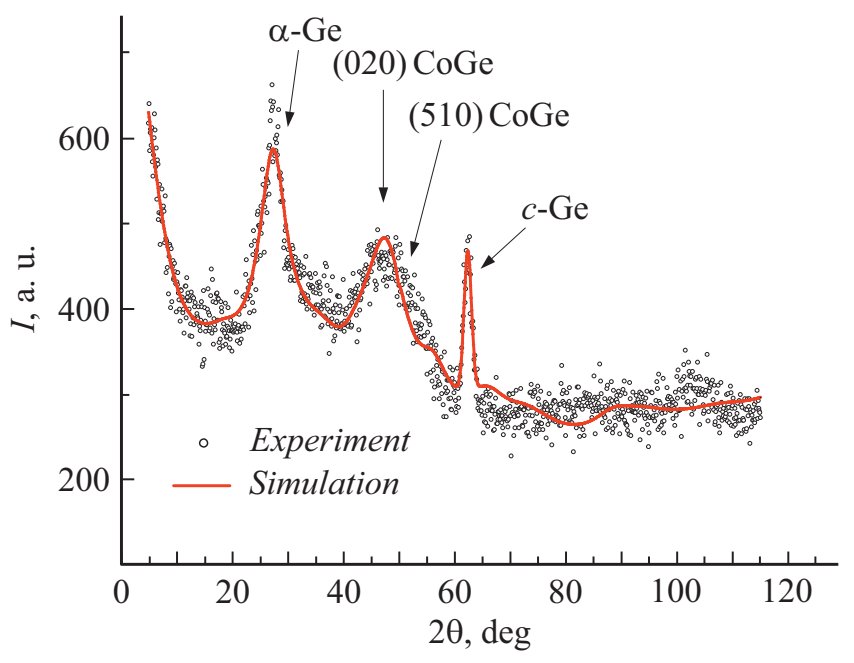

Рис. 2. Рентгенограмма поверхности пластины германия, имплантированной ионами $\mathrm{Co}^{+}$дозой $7.2 \cdot 10^{16} \mathrm{ion} / \mathrm{cm}^{2}$. Индексированы линии, принадлежащие аморфному германию, кристаллическому германию („паразитная“ линия от необлученных слоев) и германиду кобальта.

дифрактометре ДРОН-7 $\left(\mathrm{Cu} K_{\alpha}\right.$-излучение, режим скользящей геометрии под углом $2^{\circ}$ ). При таком угле падения рентгеновских лучей глубина зондирования мо- нокристаллического $\mathrm{Ge}$ составляет $\sim 40 \mathrm{~nm}$. На рис. 2 представлена дифрактограмма образца $\mathrm{Ge}$, имплантированного ионами $\mathrm{Co}^{+}$дозой $7.2 \cdot 10^{16} \mathrm{ion} / \mathrm{cm}^{2}$.

Для моделирования спектра рентгеновской дифракции была использована программа „Маud“ (версия $2.33)$ [9,10]. Дифракционные максимумы были индицированы на основе аморфного германия $\alpha$-Ge (пространственная группа $F d \overline{3} m)$ с параметром элементарной ячейки $a=5.71 \AA$ и кристаллической ячейки германида кобальта CoGe (моноклинная решетка Браве, пространственная группа $C 2 / m, a=11.63 \AA, b=3.8 \AA$, $c=4.9 \AA$, угол $\left.100.9^{\circ}\right)$. Для определения пространственного расположения атомов в ячейке $\mathrm{CoGe}$ использовались результаты работы [11]. Дифракционные максимумы металлического кобальта, оксидов кобальта и германия очень слабые и сравнимы с уровнем фона. Вместе с тем нельзя исключить образование в имплантированном слое суперпарамагнитных агломератов кобальта. Моделирование ширин линий рефлексов $\mathrm{CoGe}$ в программе „Maud“ позволило заключить, что средний размер области когерентного рассеяния фазы CoGe составляет $10 \mathrm{~nm}$, а объемное содержание в исследуемом слое фракции $\mathrm{CoGe} \sim 9 \%$. Оценка показала, что содержание атомов кобальта в $\mathrm{Ge}$ соответствует дозе имплантации ионов $\mathrm{Co}^{+}$, что подтверждает достоверность полученных результатов. 
Таким образом, в работе исследована эволюция морфологии поверхности $c$-Ge при имплантации ионами $\mathrm{Co}^{+}$с энергией $40 \mathrm{keV}$ в интервале доз $(2-8) \cdot 10^{16} \mathrm{ion} / \mathrm{cm}^{2}$. С увеличением дозы имплантации наблюдается формирование сферических наночастиц. Методом рентгеновской дифрактометрии в имплантированных слоях германия обнаружены включения фазы CoGe размером $\sim 10 \mathrm{~nm}$.

\section{Финансирование работы}

Исследование частично поддержано грантом Российского фонда фундаментальных исследований и Правительства Республики Татарстан в рамках научного проекта № 18-48-160027 p_a. Рентгенографические исследования проведены за счет государственного задания ФИЦ КазНЦ РАН.

\section{Конфликт интересов}

Авторы заявляют, что у них нет конфликта интересов.

\section{Список литературы}

[1] Romano L., Impellizzeri G., Tomasello M.V., Giannazzo F., Spinella C., Grimaldi M.G. // J. Appl. Phys. 2010. V. 107. P. 084314 (1-5). DOI: 10.1063/1.3372757

[2] Закиров Г.Г., Хайбуллин И.Б., Зарипов М.М. // ФТП. 1983. T. 17. B. 2. C. $232-234$.

[3] Rudawski N.G., Darby B.L., Yates B.R., Jones K.S., Elliman R.G., Volinsky A.A. // Appl. Phys. Lett. 2012. V. 100. P. 083111 (1-4). DOI: 10.1063/1.3689781

[4] Davis M.E. // Nature. 2002. V. 417. P. 813-821.

DOI: $10.1038 /$ nature00785

[5] Cavalcoli D., Fraboni B., Impellizzeri G., Romano L., Scavetta E., Grimaldi M.G. // Micropor. Mesopor. Mater. 2014. V. 196. P. 175-178.

DOI: 10.1016/j.micromeso.2014.05.013

[6] Ziegler J.F., Biersack J.P., Littmark U. The stopping and range of ions in solids. N.Y.: Pergamon, 1985. $321 \mathrm{p}$

[7] http://www.trim.org

[8] Wilson I.H. // J. Appl. Phys. 1982. V. 53. P. 1698-1705. DOI: $10.1063 / 1.331636$

[9] Lutterotti L. // Nucl. Instrum. Meth. Phys. Res. B. 2010. V. 268. P. 334-340. DOI: 10.1016/j.nimb.2009.09.053

[10] http://maud.radiographema.eu

[11] Audebrand N., Ellner M., Mittemeijer E.J. // Powder Diffraction. 2000. V. 15. P. 120-122.

DOI: $10.1017 / \mathrm{S} 0885715600010964$ 